\title{
Do We Have a Biocompatible Peritoneal Dialysis Fluid?
}

\author{
Shadi Hassan ${ }^{1}$, Batya Kristal ${ }^{2,3}$, Khalid Khazim ${ }^{3}$, Fadi Hassan $^{4}$, Dunia Hassan ${ }^{5}$, Kamal Hassan $^{2,3}$ \\ ${ }^{1}$ Internal Medicine Department, Carmel Medical Center, Haifa, Israel \\ ${ }^{2}$ Faculty of Medicine in the Galilee, Bar-Ilan University, Safed, Israel \\ ${ }^{3}$ Nephrology and Hypertension Department, Western Galilee Hospital, Nahariya, Israel \\ ${ }^{4}$ Sackler Faculty of Medicine, Tel Aviv University, Tel Aviv, Israel \\ ${ }^{5}$ The Ruth and Bruce Faculty of Medicine, Technion Israel Institute of Technology, Haifa, Israel \\ Email: drkamalh@hotmail.com, Kamal.Hassan@naharia.health.gov.il
}

Received April 21, 2012; revised June 7, 2012; accepted June 21, 2012

\begin{abstract}
Objective: Cardiovascular disease remains the leading cause of morbidity and mortality in patients on maintenance dialysis. Diabetes mellitus, dyslipidemia, hypertension, inflammation and hyperhomocyteinemia are major cardiovascular risk factors. Aim: To evaluate the effects of Icodextrin and amino acid peritoneal dialysis fluid (AAPDF) on these major cardiovascular risk factors looking for a more biocompatible PDF formula. Methods: 20 adult stable peritoneal dialysis patients were included in the study. 10 patients received $2 \mathrm{~L}$ Icodextrin and other 10 patients received $2 \mathrm{~L}$ AAPDF in their dialysis prescription for 8 weeks. Results: Icodextrin decreased fasting plasma glucose $(\mathrm{p}<0.001)$, LDL-C $(p=0.03)$, SBP $(p<0.01)$, DBP $(p<0.05)$ and plasma homocysteine $(p=0.002)$, and increased HDL-C $(p=$ $0.009)$, CRP $(p=0.035)$ and fibrinogen $(p=0.009)$. AAPDF did not affect fasting plasma glucose, LDL-C, HDL-C, CRP and fibrinogen but increased serum albumin $(p=0.03)$, SBP $(p<0.01)$, DBP $(p<0.05)$ and $\mathrm{P}_{\text {Hcy }}(\mathrm{p}=0.03)$. Conclusions: A biocompatible PDF should provide not only adequate dialysis and ultrafiltration but should also improve nutritional and metabolic status, blood pressure control and reduce inflammation and plasma homocyteine.
\end{abstract}

Keywords: Icodextrin; Amino Acids PDF; Homocyteine; Carbohydrates; Lipids; Inflammation

\section{Introduction}

Cardiovascular disease (CVD) remains the leading cause of morbidity and mortality in end-stage renal disease patients on maintenance dialysis [1]. Diabetes mellitus, dyslipidemia, hypertension, inflammation and hyperhomocyteinemia are major cardiovascular risk factors. Recent studies have suggested that novel risk factors, uremia or dialysis-related, are of great importance, as they act synergistically with the highly prevalent traditional risk factors for CVD in chronic kidney disease (CKD) patients [2]. Glucose based peritoneal dialysis fluids (PDFs) are usually associated with progressive loss of the osmotic gradient, concomitant reduction in ultrafiltration (UF) and to the development of hyperglycemia and dyslipidemia. Dyslipidemia increases the risk of CVD and becomes worse in peritoneal dialysis (PD) patients [3]. Up to $80 \%$ of peritoneal dialysis patients are hypertensive [4]. Hypertension plays an important role in the development of CVD in this population [4]. Elevated plasma inflammation markers associated with increased risk for CVD [5]. Almost all (97\% - 98\%) PD and hemodialysis patients have hyperhomocyteinemia that known to be associated with an increased risk of cardiovascular, cerebrovascular and venous thromboembolic diseases
[6-8]. Icodextrin and Amino acid PDF (AAPDF) considered more biocompatible PDFs. Icodextrin PDF is targeted to have more sustained oncotic effect, to reduce plasma glucose and glucose-induced lipid abnormalities, and to avoid the production of glucose degradation products (GDPs) $[9,10]$. Generally, there is some concern that Icodextrin treatment may induce a subclinical inflammatory response, both intraperitoneally and systemically [10-12]. AAPDF was designed to correct nutriational status by supplying extra nitrogen through the intraperitoneal route [13]. Although the effects of Icodextrin and AAPDF on metabolic status, blood pressure control, inflammation and plasma homocyteine were studied but some issues still controversial. Aim of this study was to evaluate the effects of Icodextrin and AAPDF on these major cardiovascular risk factors.

\section{Patients and Methods}

Randomly, 20 adult stable PD patients on continuous ambulatory peritoneal dialysis (CAPD) or automated Peritoneal Dialysis (APD) for at least 3 months and with $\mathrm{Kt} / \mathrm{V}>1.8$ were included in the study. Demographic and clinical characteristics of the enrolled subjects are listed in Table 1. The study protocol was approved by the local 
Ethics Committee and all patients gave written informed consent before participating in the study. The patients randomly assigned to receive Icodextrin or AAPDF. Ten patients received $2 \mathrm{~L}$ Icodextrin in their dialysis prescription for 8 weeks, the night dwells in CAPD subjects were substituted with 2 L Icodextrin and in APD subjects $2 \mathrm{~L}$ from their regular regimen were substituted with $2 \mathrm{~L}$ Icodextrin given as last fill. Ten patients received $2 \mathrm{~L}$ AAPDF in their dialysis prescription for 8 weeks, the second dwells in CAPD subjects were substituted with 2 $\mathrm{L}$ AAPDF and in APD subjects $2 \mathrm{~L}$ from their regular regimen were substituted with $2 \mathrm{~L}$ AAPDF given at noon. The residual renal function (RRF) was estimated by mean urea and creatinine clearance $\left(\mathrm{C}_{\mathrm{UC}}\right)$ and by the Modification of Diet in Renal Disease (MDRD) equation study [14]. At baseline the standard peritoneal equilibration test (PET) [15], and estimation of $\mathrm{Kt} / \mathrm{V}$ were performed using PD-Adequest 2.0 for Windows program (Baxter Healthcare Co., Deerfield, IL) [16]. Blood, urine and dialysate analysis were performed in both groups at baseline and 8 weeks. Blood analysis included complete blood count (CBC), glucose, low density lipoprotein cholesterol (LDL-C), high density lipoprotein cholesterol (HDL-C), triglycerides, albumin, CRP, fibrinogen, plasma homocysteine $\left(\mathrm{P}_{\mathrm{Hcy}}\right)$, folic acid, vitamin $\mathrm{B} 12$, and PTH. Urine analysis included 24-hour urinary collections for creatinine $(\mathrm{mg} / \mathrm{dl})\left(\mathrm{U}_{\mathrm{Cr}}\right)$ and urea $(\mathrm{mg} / \mathrm{dl})\left(\mathrm{U}_{\mathrm{Urea}}\right)$. Dialysate analysis included creatinine $(\mathrm{mg} / \mathrm{dl})\left(\mathrm{D}_{\mathrm{Cr}}\right)$ and glucose $(\mathrm{mg} / \mathrm{dl})\left(\mathrm{D}_{\mathrm{Glu}}\right)$. Daily urinary output (ml/day) (DUO), $\mathrm{PET}$ and $\mathrm{Kt} / \mathrm{V}$ were also evaluated at baseline and 8 weeks. $\mathrm{P}_{\text {Hcy }}$ was determined using AxSYM Homocysteine

Table 1. Characteristics of the study population.

\begin{tabular}{|c|c|c|}
\hline & Icodextrin group & AAPDF $^{\mathrm{a}}$ group \\
\hline Number & 10 & 10 \\
\hline Age (years) & $61.3 \pm 11.9$ & $59.6 \pm 20.0$ \\
\hline Male/female & $5 / 5$ & $5 / 5$ \\
\hline $\mathrm{CAPD}^{\mathrm{b}} / \mathrm{APD}^{\mathrm{c}}$ & $5 / 5$ & $5 / 5$ \\
\hline Dialysis duration (months) & $29.2 \pm 33.6$ & $28.8 \pm 17.3$ \\
\hline $\mathrm{PET}^{\mathrm{d}}: \mathrm{HATs}^{\mathrm{e}} / \mathrm{LATs}^{\mathrm{f}}$ & $5 / 5$ & $5 / 5$ \\
\hline $\mathrm{Kt} / \mathrm{V}$ & $2.41 \pm 0.4$ & $2.39 \pm 0.4$ \\
\hline $\begin{array}{l}\text { Vitamin B12 }(\mathrm{pg} / \mathrm{ml}) \\
\text { (Normal:160 - 680) }\end{array}$ & $598.3 \pm 280.3$ & $610.9 \pm 330.5$ \\
\hline $\begin{array}{l}\text { Folic acid }(\mathrm{ng} / \mathrm{mL}) \\
(\text { Normal:150 - 700) }\end{array}$ & $760.0 \pm 385.0$ & $771.2 \pm 318.1$ \\
\hline PTH (pg/ml) (normal:10 - 60) & $313 \pm 185$ & $301 \pm 158$ \\
\hline \multicolumn{3}{|l|}{ Underlying cause: } \\
\hline Diabetes mellitus & 5 & 5 \\
\hline Primary hyperoxaluria type 1 & 2 & 2 \\
\hline $\mathrm{APKD}^{\mathrm{g}}$ & 1 & 1 \\
\hline Unknown & 2 & 2 \\
\hline
\end{tabular}

a: Amino Acid Peritoneal Dialysis Fluid; b: Continuous ambulatory peritoneal dialysis; c: Automated peritoneal dialysis; $d$ : Peritoneal equilibration test; e: High average transporters; f: Low average transporters; g: Adult Polycystic Kidney Disease. assay (Produced by Axis-Shied, Dundee, UK for Abbott laboratories, Abbott park, IL 60064, USA). Statistical methods: Qualitative variables were described as incidences and percentages. Quantitative variables were described as means and standard deviations. Repeated Measures tests were used to evaluate the effects of Icodextrin and AAPDF on RRF, DUO, UF, D/P $\mathrm{P}_{\mathrm{Cr}}, \mathrm{D}_{\mathrm{Glu}}, \mathrm{D}_{\mathrm{Cr}}$, fasting glucose, plasma lipids, plasma inflammation markers, body weight, blood pressure and $\mathrm{P}_{\mathrm{Hcy}}$. Repeated Measures tests were also used to evaluate the effects of PD modality, peritoneal membrane characteristics, Kt/V, gender, cause of CKD and hemoglobin on $\mathrm{P}_{\mathrm{Hcy}}$. Linear regression was used to evaluate the correlation between $\mathrm{P}_{\text {Hcy }}$ and RRF, DUO, PD duration, age, body weight, PTH and hemoglobin levels. Linear regression was also used to evaluate the correlation between degree of increment in UF ( $\triangle$ Net UF) and the degree of reduction in $\mathrm{P}_{\text {Hcy }}$ $\left(\Delta \mathrm{P}_{\mathrm{Hcy}}\right)$ as well as between the degree of increment in $\mathrm{D} / \mathrm{P}_{\mathrm{Cr}}\left(\Delta \mathrm{D} / \mathrm{P}_{\mathrm{Cr}}\right)$ and $\Delta \mathrm{P}_{\mathrm{Hcy}}$.

\section{Results}

Repeated measures analysis revealed that Icodextrin and AAPDF did not affect the RRF or DUO (Table 2). No linear correlation was found between the RRF and $\mathrm{P}_{\mathrm{Hcy}}$. Icodextrin increased UF $(\mathrm{p}=0.003)$ and $\mathrm{D} / \mathrm{P}_{\mathrm{Cr}}(\mathrm{p}<0.001)$ (Table 2). Icodextrin, as well AAPDF decreased $\mathrm{D}_{\mathrm{Glu}}(\mathrm{p}$ $=0.02$ ) (Table 2).

Table 2. Effects of Icodextrin and AAPDF on RRF, DUO, $\mathrm{UF}, \mathrm{D} / \mathrm{P}_{\mathrm{Cr}}$ and $\mathrm{D}_{\mathrm{Glu}}$.

\begin{tabular}{|c|c|c|c|}
\hline & \multicolumn{3}{|c|}{ Icodextrin group } \\
\hline & Baseline & 8 Weeks & $\mathrm{p}$ \\
\hline $\mathrm{P}_{\mathrm{Hcy}}(\mu \mathrm{mol} / \mathrm{L})$ & $29.1 \pm 21.8$ & $14.8 \pm 5.3$ & 0.002 \\
\hline $\mathrm{C}_{\mathrm{UC}}\left(\mathrm{ml} / \mathrm{min} / 1.73 \mathrm{~m}^{2}\right)$ & $10.1 \pm 2.3$ & $9.5 \pm 2.9$ & n.s. \\
\hline $\begin{array}{l}\text { eGFR } \\
\left(\mathrm{ml} / \mathrm{min} / 1.73 \mathrm{~m}^{2}\right)\end{array}$ & $8.3 \pm 2.4$ & $8.1 \pm 2.0$ & n.s. \\
\hline DUO (L/day) & $0.8 \pm 0.4$ & $0.75 \pm 0.3$ & n.s. \\
\hline UF (L/day) & $0.98 \pm 0.1$ & $1.22 \pm 1.3$ & 0.003 \\
\hline $\mathrm{D} / \mathrm{P}_{\mathrm{Cr}}$ & $0.54 \pm 0.1$ & $0.79 \pm 0.1$ & $<0.001$ \\
\hline \multirow[t]{3}{*}{$D_{\mathrm{Glu}}(\mathrm{mg} / \mathrm{dl})$} & $1035.8 \pm 438.1$ & $901.8 \pm 354.9$ & 0.016 \\
\hline & \multicolumn{3}{|c|}{ AAPDF group } \\
\hline & Baseline & 8 weeks & $\mathrm{p}$ \\
\hline $\mathrm{P}_{\text {Hсу }}{ }^{\mathrm{a}}(\mu \mathrm{mol} / \mathrm{L})$ & $26.6 \pm 17.0$ & $36.4 \pm 15.6$ & 0.03 \\
\hline $\mathrm{C}_{\mathrm{UC}}{ }^{\mathrm{b}}\left(\mathrm{ml} / \mathrm{min} / 1.73 \mathrm{~m}^{2}\right)$ & $10.2 \pm 3.7$ & $9.7 \pm 3.3$ & n.s. \\
\hline $\begin{array}{l}\mathrm{eGFR}_{\mathrm{MDRD}}{ }^{\mathrm{c}} \\
\left(\mathrm{ml} / \mathrm{min} / 1.73 \mathrm{~m}^{2}\right)\end{array}$ & $8.1 \pm 2.3$ & $8.0 \pm 2.0$ & n.s. \\
\hline $\mathrm{DUO}^{\mathrm{d}}$ (L/day) & $0.7 \pm 0.3$ & $0.6 \pm 0.4$ & n.s. \\
\hline $\mathrm{UF}^{\mathrm{e}}$ (L/day) & $0.99 \pm 0.2$ & $0.97 \pm 0.2$ & n.s. \\
\hline $\mathrm{D} / \mathrm{P}_{\mathrm{Cr}}^{\mathrm{f}}$ & $0.64 \pm 0.1$ & $0.61 \pm 0.2$ & n.s. \\
\hline $\mathrm{D}_{\mathrm{Glu}}{ }^{\mathrm{g}}(\mathrm{mg} / \mathrm{dl})$ & $981.4 \pm 446.8$ & $854.5 \pm 435.5$ & 0.02 \\
\hline
\end{tabular}


The basal levels of $\mathrm{HbA}_{1 \mathrm{C}}$ in the two study groups were similar $(4.9 \% \pm 0.7 \%$ in Icodextrin group and $5.1 \%$ $\pm 1.5 \%$ in AAPDF group). Icodextrin decreased fasting glucose $(\mathrm{p}<0.001)$, LDL-C $(\mathrm{p}=0.03)$ and triglycerides $(p=0.04)$, and increased HDL-C levels $(p=0.009)$ (Table 3). AAPDF did not affect glucose and lipid metabolism (Table 3).

Basal levels of inflammation markers were similar in both study groups. Basal serum CRP and fibrinogen levels were elevated in both study groups. Compared to AAPDF, Icodextrin increased serum CRP $(p=0.035)$ and fibrinogen levels $(p=0.009)$ (Table 3). AAPDF, in contrast to Icodextrin, increased serum albumin $(\mathrm{p}=0.03)$ (Table 3). Icodextrin decreased body weight $(p=0.002)$, SBP $(p<0.01)$ and DBP $(p<0.05)$ while AAPDF increased body weight $(\mathrm{p}=0.002)$, SBP $(\mathrm{p}<0.01)$ and DBP $(\mathrm{p}<0.05)$ (Table 3).

Table 3. Effects of Icodextrin and AAPDF on carbohydrates, lipids, inflammation and blood pressure.

\begin{tabular}{|c|c|c|c|}
\hline & \multicolumn{3}{|c|}{ Icodextrin group } \\
\hline & Baseline & 8 weeks & $\mathrm{p}$ \\
\hline Fasting glucose (mg/dl) & $141.1 \pm 39.9$ & $119.3 \pm 29.1$ & $\begin{array}{c}<0.00 \\
1\end{array}$ \\
\hline LDL-C (mg/dl) & $102.3 \pm 33.3$ & $89.6 \pm 22.0$ & 0.03 \\
\hline HDL-C (mg/dl) & $35.6 \pm 10.1$ & $40.7 \pm 11.8$ & 0.009 \\
\hline $\mathrm{TG}(\mathrm{mg} / \mathrm{dl})$ & $272.4 \pm 67.0$ & $221.4 \pm 74.8$ & 0.04 \\
\hline Albumin(gr/dl) & $3.6 \pm 0.4$ & $3.6 \pm 0.3$ & n.s. \\
\hline $\mathrm{CRP}(0-5 \mathrm{mg} / \mathrm{L})$ & $9.5 \pm 6.5$ & $22.4 \pm 16.5$ & 0.035 \\
\hline $\begin{array}{l}\text { Fibrinogen } \\
(200-400 \mathrm{mg} / \mathrm{dl})\end{array}$ & $835.1 \pm 126.5$ & $1066.1 \pm 199.8$ & 0.009 \\
\hline Body weight (kg) & $80.4 \pm 14.1$ & $78.5 \pm 14.7$ & 0.002 \\
\hline $\mathrm{SBP}(\mathrm{mmHg})$ & $149.5 \pm 35.5$ & $131.4 \pm 21.9$ & $<0.01$ \\
\hline \multirow[t]{3}{*}{ DBP (mmHg) } & $79.0 \pm 14.5$ & $72.8 \pm 9.9$ & $<0.05$ \\
\hline & \multicolumn{3}{|c|}{ AAPDF group } \\
\hline & Baseline & 8 weeks & $\mathrm{p}$ \\
\hline Fasting glucose (mg/dl) & $138.4 \pm 76.2$ & $142.2 \pm 86.6$ & n.s. \\
\hline $\mathrm{LDL}^{\mathrm{a}}(\mathrm{mg} / \mathrm{dl})$ & $117.6 \pm 25.9$ & $112.97 \pm 21.1$ & n.s. \\
\hline $\mathrm{HDL}^{\mathrm{b}}(\mathrm{mg} / \mathrm{dl})$ & $42.0 \pm 9.4$ & $45.0 \pm 11.6$ & n.s. \\
\hline $\mathrm{TG}^{\mathrm{c}}(\mathrm{mg} / \mathrm{dl})$ & $186.4 \pm 96.6$ & $176.3 \pm 62.7$ & n.s. \\
\hline Albumin (gr/dl) & $3.5 \pm 0.4$ & $4.3 \pm 0.5$ & 0.03 \\
\hline $\mathrm{CRP}(0-5 \mathrm{mg} / \mathrm{L})$ & $12.6 \pm 26.0$ & $10.4 \pm 18.3$ & n.s. \\
\hline $\begin{array}{l}\text { Fibrinogen } \\
(200-400 \mathrm{mg} / \mathrm{dl})\end{array}$ & $999.6 \pm 189.6$ & $973.0 \pm 231.4$ & n.s. \\
\hline Body weight (kg) & $71.6 \pm 15.0$ & $72.5 \pm 15.0$ & 0.002 \\
\hline $\mathrm{SBP}^{\mathrm{d}}(\mathrm{mmHg})$ & $138.7 \pm 28.4$ & $146.6 \pm 26.4$ & $<0.01$ \\
\hline $\mathrm{DBP}^{\mathrm{e}}(\mathrm{mmHg})$ & $75.4 \pm 12.3$ & $80.1 \pm 11.8$ & $<0.05$ \\
\hline
\end{tabular}

a: Low density lipoprotein cholesterol; b: High density lipoprotein cholesterol; c: Triglycerides; d: Systolic blood pressure; e: Diastolic blood pressure.
Hyperhomocysteinemia was identified in $84 \%$ of the study subjects at baseline. Icodextrin decreased $\mathrm{P}_{\text {Hcy }}(\mathrm{p}=$ 0.002) (Table 2). AAPDF increased $\mathrm{P}_{\mathrm{Hcy}}(\mathrm{p}=0.03)$ (Table 2). Furthermore, in Icodextrin group, a linear correlation was found between the degree of increment in UF $(\Delta \mathrm{UF})$ and the degree of reduction in $\mathrm{P}_{\mathrm{Hcy}}\left(\Delta \mathrm{P}_{\mathrm{Hcy}}\right)(\mathrm{p}<$ $\left.0.001, \mathrm{R}^{2}=0.962\right)$ (Figure 1), and between the degree of increment in $\mathrm{D} / \mathrm{P}_{\mathrm{Cr}}\left(\Delta \mathrm{D} / \mathrm{P}_{\mathrm{Cr}}\right)$ and $\Delta \mathrm{P}_{\text {Hcy }}\left(\mathrm{p}<0.001, \mathrm{R}^{2}=\right.$ 0.836) (Figure 2).

Icodextrin decreased $\mathrm{P}_{\mathrm{Hcy}}$ in both CAPD and APD patients $(p=0.033)$, in low average transporter patients (LATs) $(\mathrm{p}=0.006)$, in PD patients with $\mathrm{Kt} / \mathrm{V}>2(\mathrm{p}=$ $0.04)$ or $\mathrm{Kt} / \mathrm{V} \leq 2(\mathrm{p}=0.003)$ and in non diabetic patients $(p=0.039)$ (Table 4). LATs had a higher basal $\mathrm{P}_{\text {Hcy }}$ compared with high-average transporter patients (HATs) $(\mathrm{p}=0.015)$ (Table 4). HATs had lower $\mathrm{P}_{\text {Hcy }}$ which were in the upper normal limits (Table 4).

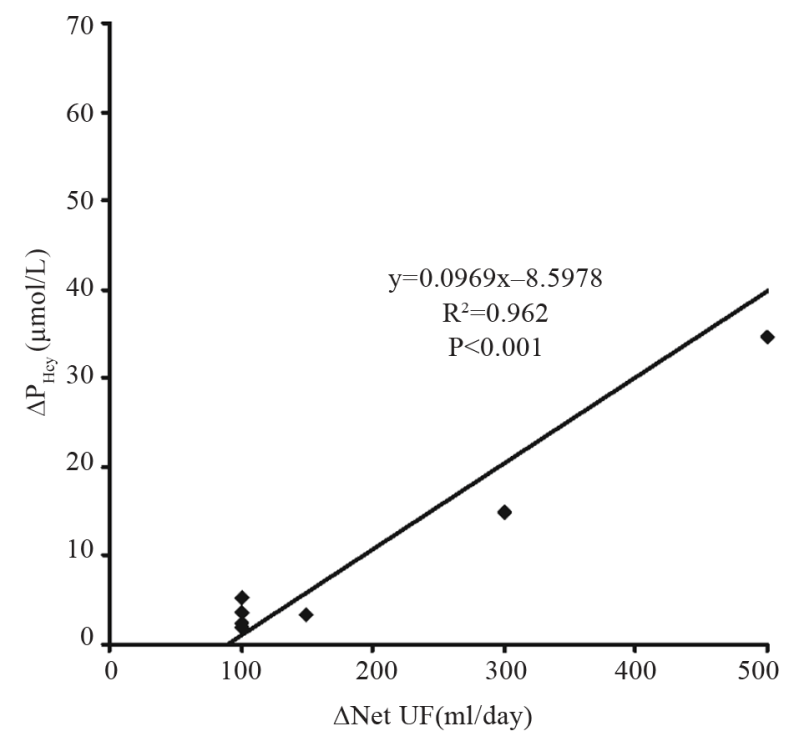

Figure 1. The correlation between $\Delta \mathbf{P}_{\mathrm{Hcy}}$ and $\Delta \mathrm{Net} \mathrm{UF}$ in the extraneal group.

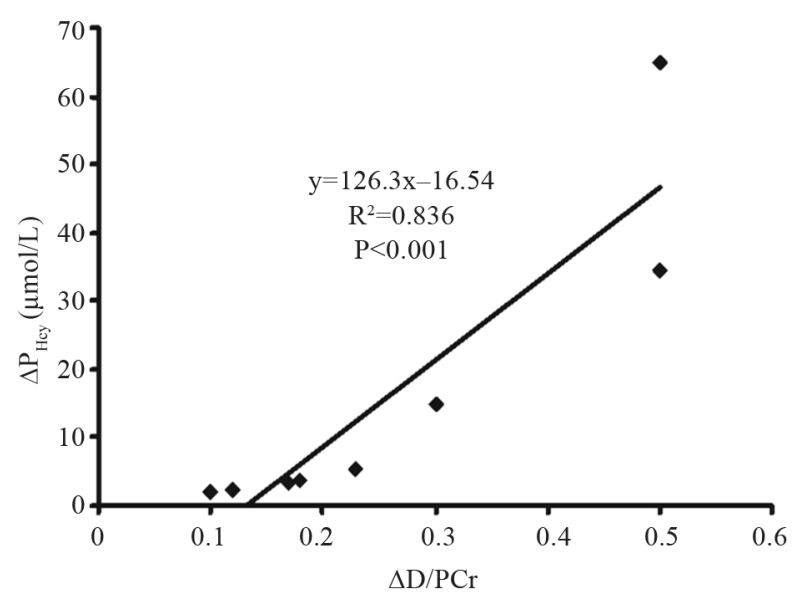

Figure 2. The correlation between $\Delta \mathbf{P}_{\mathrm{Hcy}}$ and $\Delta \mathbf{D} / \mathbf{P}_{\mathrm{Cr}}$ in the extraneal group. 
Table 4. Effects of $P D^{a}$ modality, peritoneal membrane characteristics, $\mathrm{Kt} / \mathrm{V}$, gender and diabetes mellitus on $\mathbf{P}_{\mathrm{Hcy}}$.

\begin{tabular}{|c|c|c|c|}
\hline & \multicolumn{3}{|c|}{$\mathrm{P}_{\mathrm{Hcy}}^{\mathrm{b}}(\mu \mathrm{mol} / \mathrm{L})$ in Icodextrin group } \\
\hline & Baseline & 8 weeks & $\mathrm{p}$ \\
\hline $\mathrm{CAPD}^{\mathrm{c}}$ & $33.0 \pm 26.3$ & $14.7 \pm 6.2$ & 0.033 \\
\hline $\mathrm{APD}^{\mathrm{d}}$ & $24.3 \pm 17.0$ & $14.8 \pm 5.0$ & 0.033 \\
\hline $\mathrm{p}$ & n.s. & & \\
\hline $\mathrm{LATs}^{\mathrm{e}}$ & $46.4 \pm 23.2$ & $17.2 \pm 5.3$ & 0.006 \\
\hline HATs $^{\mathrm{f}}$ & $15.3 \pm 3.0$ & $12.8 \pm 5.1$ & n.s. \\
\hline $\mathrm{P}$ & 0.015 & & \\
\hline $\mathrm{Kt} / \mathrm{V} \leq 2$ & $46.9 \pm 32.5$ & $19.5 \pm 2.7$ & 0.003 \\
\hline $\mathrm{Kt} / \mathrm{V}>2$ & $20.2 \pm 7.3$ & $15.9 \pm 6.2$ & 0.04 \\
\hline $\mathrm{p}$ & 0.05 & & \\
\hline $\mathrm{DM}^{\mathrm{g}}$ & $24.5 \pm 7.9$ & $17.0 \pm 7.4$ & n.s. \\
\hline Non DM & $31.4 \pm 6.7$ & $13.7 \pm 4.4$ & 0.039 \\
\hline \multirow[t]{3}{*}{$\mathrm{p}$} & n.s. & & \\
\hline & \multicolumn{3}{|c|}{$\mathrm{P}_{\text {Hcy }}(\mu \mathrm{mol} / \mathrm{L})$ in AAPDF group } \\
\hline & Baseline & 8 weeks & $\mathrm{p}$ \\
\hline CAPD & $26.72 \pm 7.2$ & $33.6 \pm 15.7$ & n.s. \\
\hline APD & $26.52 \pm 24.5$ & $31.12 \pm 34.9$ & n.s. \\
\hline $\mathrm{p}$ & n.s. & & \\
\hline LATs & $37.5 \pm 18.8$ & $48.5 \pm 28.5$ & n.s. \\
\hline HATs & $15.8 \pm 2.1$ & $16.2 \pm 3.1$ & n.s. \\
\hline $\mathrm{p}$ & 0.015 & & \\
\hline $\mathrm{Kt} / \mathrm{V} \leq 2$ & $32.3 \pm 25.5$ & $38.5 \pm 36.6$ & n.s. \\
\hline $\mathrm{Kt} / \mathrm{V}>2$ & $22.8 \pm 9.4$ & $28.3 \pm 17.9$ & n.s. \\
\hline $\mathrm{p}$ & 0.05 & & \\
\hline $\mathrm{DM}$ & $28.7 \pm 5.1$ & $37.0 \pm 3.9$ & n.s. \\
\hline Non DM & $30.0 \pm 19.5$ & $38.9 \pm 28.4$ & n.s. \\
\hline $\mathrm{p}$ & n.s. & & \\
\hline
\end{tabular}

a: Peritoneal dialysis; b: Plasma homocysteine; c: Continuous ambulatory peritoneal dialysis; d: Automated peritoneal dialysis, HATs $=$ High average transporters; e: Low average transporters; f: High average transporters; g: Diabetes mellitus.

AAPDF increased $\mathrm{P}_{\text {Hcy }}(\mathrm{p}=0.03)$ (Table 2).

Linear regression analysis did not show any correlation between $\mathrm{P}_{\mathrm{Hcy}}$ and age, gender, body weight, duration of PD, DUO, hemoglobin and PTH levels in both Icodextrin and AAPDF groups.

\section{Discussion}

Long-term systemic exposure of glucose caused by conventional PD solutions has been well recognized to cause metabolic and cardiovascular abnormalities, which contribute to the morbidities seen in PD patients. Several studies have shown that conventional solutions damage mesothelial cells and peritoneal blood vessels leading to functional impairment $[17,18]$. Besides its effects on the peritoneal membrane, rapid absorption of glucose during a dwell leads to loss of osmotic gradient and diminished ultrafiltration as well as to the development of hyperglycemia and associated hyperinsulinemia in both diabetic as well as nondiabetic patients [19]. The high levels of dextrose and the lactate acidic buffer make the conventional solutions nonphysiologic and nonbiocompatible. Introducing the newer solutions that designed to be more biocompatible by either, containing physiologic buffer bicarbonate, or having lower GDP concentration, and/or substituting glucose with alternative osmotic agents, like polyglucose or amino acids were targeted to ameliorate the complications of conventional dextrose solutions [20-22]. It is postulated that newer PD solutions containing lower levels of GDPs are less nephrotoxic, and hence may preserve RRF longer. Additionally, the effect of fluid status on preservation of RRF cannot be ignored.

In the present study, Icodextrin and AAPDF did not affect RRF (Table 2). Icodextrin improved glucose control and lipid profile including significant decrease in LDL-C and triglyceride levels as well as significant increase in HDL-C (Table 3). Similar results were reported by Bredie et al. [23].

It is well known that the major reason for the elevation of blood pressure in PD patients is volume overload. Icodextrin improved blood pressure control by improving UF and decreasing body weight (Tables $\mathbf{2}$ and $\mathbf{3}$ ).

The effects of Icodextrin on inflammation status in PD patients are controversial [11,12]. Martikainen et al. showed that Icodextrin use was resulted in subclinical inflammatory response [11]. In contrast, Lin et al. reported that Icodextrin decreased CRP [12]. In this study the basal serum CRP and fibrinogen levels were similar and elevated in both study groups (Table 3). Icodextrin use was accompanied by a rise in plasma CRP and fibrinogen levels (Table 3). There is a concern that Icodextrin use may induce a subclinical inflammatory response, both intraperitoneally and systemically. Accordingly, Icodextrin that lowered GDPs levels and designed to preserve the peritoneal membrane and to improve glucose and lipid control, seems to intensify systemic inflammation.

Hyperhomocysteinemia was identified in $84 \%$ of our study subjects compared to the $97 \%-98 \%$ reported by Van Guldener [24]. The significant rise in $\mathrm{D} / \mathrm{P}_{\mathrm{Cr}}$ and UF as well as the linear correlations between $\Delta \mathrm{P}_{\text {Hcy }}$ and $\Delta$ NetUF, and between $\Delta \mathrm{P}_{\mathrm{Hcy}}$ and $\Delta \mathrm{D} / \mathrm{P}_{\mathrm{Cr}}$ in the Icodextrin group, suggest better peritoneal clearances of Hcy compared to standard glucose-based fluids and AAPDF (Table 2, Figures 1 and 2). Similar results were reported by Czupryniak et al. [25].

It is well known that AAPDF improve nutritional status in malnourished PD patients. Although increased serum albumin levels and did not affect UF, glucose and lipid metabolism, and inflammation status, AAPDF increased body weight, SBP, DBP and $\mathrm{P}_{\text {Hcy }}$ levels $(\mathrm{p}=$ 
$0.002, \mathrm{p}<0.01, \mathrm{p}<0.05, \mathrm{p}=0.03$-respectively) (Tables 2 and 3). The increase in $P_{\text {Hcy }}$ in the AAPDF group is, most likely, related to methionine, a precursor of Hcy, absorption as well as to the decrease in $\mathrm{D} / \mathrm{P}_{\mathrm{Cr}}$ and $\mathrm{UF}$ in the AAPDF group (Table 2). Then, AAPDF that introduced to improve nutritional status and survival may contribute to the unfavorable rise of $\mathrm{P}_{\mathrm{Hcy}}$. The rise in $\mathrm{P}_{\mathrm{Hcy}}$ in PD patients treated with AAPDF described also in previous studies [26,27].

End stage renal disease patients are unable to excrete the daily acid load. The standard PDFs, Icodextrin and AAPDF use lactate as a buffer that, by its acidic $\mathrm{pH}$, causes harmful effects on the peritoneal cells [17]. In contrast, bicarbonate-based PDFs include a physiologic buffer with neutral $\mathrm{pH}$, cause less peritoneal damage [28].

The relationships between the PD modality, the peritoneal membrane characteristics and $\mathrm{Kt} / \mathrm{V}$, and $\mathrm{P}_{\mathrm{Hcy}}$ remain a controversial issue $[29,30]$. Basal $\mathrm{P}_{\mathrm{Hcy}}$ was elevated and not different in the two study groups and all subgroups apart from HATs (Table 4). In the Icodextrin group $\mathrm{P}_{\text {Hcy }}$ decreased in both PD modalities $(\mathrm{p}=0.033)$ (Table 3). On the other hand, AAPDF increase $\mathrm{P}_{\text {Hcy }}(\mathrm{p}=$ 0.033) (Table 2). This may be due to its low osmotic drive and as a result of the absorption of methionine through the peritoneal membrane. These results suggest that the peritoneal membrane characteristics and the composition of the PDF have an important role in the peritoneal elimination of Hcy.

Basal $\mathrm{P}_{\mathrm{Hcy}}$ in HATs were near normal in both study groups (Table 4). It may be related to the higher solute clearances across the peritoneal membrane in HATs.

Basal $\mathrm{P}_{\mathrm{Hcy}}$ was marginally lower in subjects with $\mathrm{Kt} / \mathrm{V}$ $>2$ compared to those with $\mathrm{Kt} / \mathrm{V} \leq 2(\mathrm{p}=0.05)$ (Table 4). Icodextrin, but not AAPDF, significantly decreased $\mathrm{P}_{\mathrm{Hcy}}$ in $\mathrm{PD}$ patients with $\mathrm{Kt} / \mathrm{V}>2$, in those with $\mathrm{Kt} / \mathrm{V} \leq 2$ and in non diabetic patients (Table 4). Therefore, Icodextrin may influence the atherosclerotic outcomes through Hcy-lowering effects, as it was stated previously by Docloux et al [29].

No associations between age, gender, body weight, duration of $\mathrm{PD}$, hemoglobin, $\mathrm{PTH}, \mathrm{RRF}$ and DUO and $\mathrm{P}_{\mathrm{Hcy}}$ were found.

In summary: Higher UF, higher $\mathrm{D} / \mathrm{P}_{\mathrm{Cr}}, \mathrm{HATs}, \mathrm{Kt} / \mathrm{V}>$ 2 , non diabetic patients and Icodextrin use were associated with decline in $\mathrm{P}_{\text {Hcy }}$. Conversely, lower UF, lower $\mathrm{D} / \mathrm{P}_{\mathrm{Cr}}$, LATs, $\mathrm{Kt} / \mathrm{V} \leq 2$, diabetic patients and AAPDF use were associated with rise in $\mathrm{P}_{\mathrm{Hcy}}$.

Although it exhibited favorable effects on metabolic status, blood pressure control and $\mathrm{P}_{\mathrm{Hcy}}$ levels, Icodextrin seems to intensify systemic inflammation. On the other hand, although it did not seem to affect adversely the metabolic status and systemic inflammation, AAPDF increased $\mathrm{P}_{\mathrm{Hcy}}$ and blood pressure.

The results of the present study suggested that the use of Icodextrin and AAPDF was associated with beneficial effects as well as with considerable harmful consequences that may adversely affect the prognosis and survival of PD patients.

\section{Conclusion}

A new PDF containing a mixture of a biocompatible substance, amino acids without methionine, lower glucose and GDPs content, and neutral $\mathrm{pH}$ will provide sustained oncotic effect, adequate dialysis and ultrafiltration as well as will improve nutritional status and metabolic profile, reduce inflammation, plasma homocyteine and blood pressure. A PDF with those properties will preserve the peritoneal membrane and improve the prognosis and survival of peritoneal dialysis patients.

\section{Acknowledgements}

The authors would like to thank Prof. Ben Ami Sela, Clinical Biochemistry Laboratory-Sheba Medical Center, Tel Hashomer, Israel for his assistance in determination of $\mathrm{P}_{\mathrm{Hcy}}$. We also would like to thank Tobie Kuritsky for her assistance in editing our manuscript.

\section{REFERENCES}

[1] P. S. Parfrey and J. D. Harnett, "Long Term Cardiac Morbidity and Mortality during Dialysis Therapy," Advanced Nephrology, Vol. 23, 1994, pp. 311-330.

[2] S. H. Park, P. Stenvinkel and B. Lindholm, "Cardiovascular Biomarkers in Chronic Kidney Disease," Journal of Renal Nutrition, Vol. 22, No. 1, 2012, pp. 120-127. doi:10.1053/j.jrn.2011.10.021

[3] A. H. Mitwalli, A. A. Alam, J. S. Al Wakeel and A. C. Isnani, "Dyslipidemia in Dialysis Patients," Saudi Journal of Kidney Disease and Transplantation, Vol. 22, No. 4, 2011, pp. 689-694.

[4] L. M. Ortega and B. J. Materson, "Hypertension in Peritoneal Dialysis Patients: Epidemiology, Pathogenesis, and Treatment," Journal of the American Society of Hypertension, Vol. 5, No. 3, 2011, pp. 128-136. doi:10.1016/i.jash.2011.02.004

[5] M. Moriishi and H. Kawanishi, "Icodextrin and Intraperitoneal Inflammation," Peritoneal Dialysis International, Vol. 28, Suppl. 3, 2008, pp. S96-S100.

[6] T. Huang, G. Yuan, Z. Zhang, Z. Zou and D. Li, "Cardiovascular Pathogenesis in Hyperhomocysteinemia," Asia Pacific Journal of Clinical Nutrition, Vol. 17, No. 1, 2008, pp. 8-16.

[7] C. van Guldener and F. Stam, "Stehouwer CDA. Homocysteine Metabolism in Renal Failure," Kidney International, Vol. 59, Suppl. 78, 2001, pp. S234-S237. doi:10.1046/j.1523-1755.2001.07859.x

[8] M. M. Sagheb, M. A. Ostovan, Z. Sohrabi, E. Atabati, G. A. Raisjalai and J. Roozbeh, "Hyperhomocysteinemia and Cardiovascular Risks in Hemodialysis Patients," Saudi 
Journal of Kidney Diseases and Transplantation, Vol. 21, No. 5, 2010, pp. 863-866.

[9] L. A. Cooker, C. J. Holmes and C. M. Hoff, "Biocompatibility of Icodextrin," Kidney International, Vol. 62, Suppl. 81, 2002, pp. S34-S45. doi:10.1046/j.1523-1755.62.s81.6.x

[10] M. Canbakan and G. M. Sahin, "Icodextrine and Insulin Resistance in Continuous Ambulatory Peritoneal Dialysis Patients," Renal Failure, Vol. 29, No. 3, 2007, pp. 289293. doi:10.1080/08860220601166271

[11] T. A. Martikainen, A. M. Teppo, C. Grönhagen-Riska and A. V. Ekstrand, "Glucose-Free Dialysis Solutions: Inductors of Inflammation or Preservers of Peritoneal Membrane?" Peritoneal Dialysis International, Vol. 25, No. 5, 2005, pp. 453-460.

[12] W. Lin, Y. C. Chen, M. S. Wu, H. J. Hsu, C. Y. Sun, Y. K.Lin and I. W. Wu, "Icodextrin Dialysate Improves Nutritional and Inflammatory Profiles in Peritoneal Dialysis Patients," Renal Failure, Vol. 31, No. 2, 2009, pp. 98-105. doi: $10.1080 / 08860220802595500$

[13] F. K. Li, L. Y.Chan , J. C. Woo, et al., "A 3-Year, Prospective, Randomized, Controlled, Study on Amino Acid Dialysate in Patients on CAPD," American Journal of Kidney Diseases, Vol. 42, No. 1, 2003, pp. 173-183. doi:10.1016/S0272-6386(03)00421-9

[14] A. S. Levey, J. P. Bosch, J. B. Lewis, T. Greene, N. Rogers and D. Roth, "A More Accurate Method to Estimate Glomerular Filtration Rate from Serum Creatinine: A New Prediction Equation, Modification of Diet in Renal Disease Study Group," Annals of Internal Medicine, Vol. 130, No. 6, 1999, pp. 461-470.

[15] Z. J. Twardowski, "Clinical Value of Standardized Equilibration Tests in CAPD Patients," Blood Purification, Vol. 7, No. 2-3, 1989, pp. 95-108. doi:10.1159/000169582

[16] G. Amici, S. Mastrosimone, G. Da Rin, C. Bocci and A. Bonadonna, "Clinical Validation of PD Adequest Software: Modeling Error Assessment," Peritoneal Dialysis International, Vol. 18, No. 3, 1998, pp. 317-321.

[17] H. Ha, M. R. Yu, H. N. Choi, M. K. Cha, H. S. Kang, M. H. Kim and H. B. Lee, "Effects of Conventional and New Peritoneal Dialysis Solutions on Human Peritoneal Mesothelial Cell Viability and Proliferation," Peritoneal Dialysis International, Vol. 20, Suppl. 5, 2000, pp. S10S18.

[18] R. T. Krediet, M. M. Zweers, A. C. vander Wal and D. J. Struijk, "Neoangiogenesis in the Peritoneal Membrane," Peritoneal Dialysis International, Vol. 20, Suppl. 2, 2000, pp. S19-S25.

[19] J. Delarue and C. Maingourd, "Acute Metabolic Effects of Dialysis Fluids during CAPD," American Journal of Kidney Diseases, Vol. 37, Suppl. 2, 2001, pp. S103-S107. doi:10.1053/ajkd.2001.20762

[20] N. Posthuma, P. M. ter Wee, A. J. Donker, P. L. Oe, E. M. Peers and H. A. Verbrugh, "Assesement of the Effectiveness, Safety, and Biocompatibility of Icodextrin in Automated Peritoneal Dialysis. The Dextrin in APD in Amsterdam (DIANA) Group," Peritoneal Dialysis Interna- tional, Vol. 20, Suppl. 2, 2000, pp. S106-S113.

[21] T. W. Kao, H. F. Chuang, K. Y. Hung, K. D. Wu and T. J. Tsai, "Rate of Decline of Residual Renal Function is Associated with All-Cause Mortality and Technique Failure in Patients on Long-Term Peritoneal Dialysis," Nephrology Dialysis Transplantation, Vol. 24, No. 9, 2009, pp. 2909-2914. doi:10.1093/ndt/gfp056

[22] S. Kim, J. Oh, S. Kim, W. Chung, C. Ahn, S. G. Kim and K. H. Oh, "Benefits of Biocompatible PD Fluid for Preservation of Residual Renal Function in Incident CAPD Patients: A 1-Year Study," Nephrology Dialysis Transplantation, Vol. 24, No. 9, 2009, pp. 2899-2908. doi:10.1093/ndt/gfp054

[23] S. J. Bredie, F. H. Bosch, P. N. Demacker, A. F. Stalenhoef and R. Van Leusen, "Effects of Peritoneal Dialysis with an Overnight Icodextrin Dwell on Parameters of Glucose and Lipid Metabolism," Peritoneal Dialysis International, Vol. 21, No. 3, 2001, pp. 275-281.

[24] C. Van Guldener, "Why is Homocysteine Elevated in Renal Failure and What Can Be Expected from Homocysteine-Lowering?" Peritoneal Dialysis International, Vol. 21, No. 5, 2006, pp. 1161-1166. doi:10.1093/ndt/gf1044

[25] A. Czupryniak, M. Nowicki, G. Chwatko, A. Jander and E. Bald, "Peritoneal Clearance of Homocysteine with Icodextrin or Standard Glucose Solution Exchange," $\mathrm{Ne}$ phrology (Carlton), Vol. 10, No. 6, 2005, pp. 571-575.

[26] H. F. Brulez, C. van Guldener, A. J. Donker and P. M. Ter Wee, "The Impact of an Amino Acid-Based Peritoneal Dialysis Fluid on Plasma Total Homocysteine Levels, Lipid Profile and Body Fat Mass," Nephrology Dialysis Transplantation, Vol. 14, No. 1, 1999, pp. 154-159. doi:10.1093/ndt/14.1.154

[27] S. Y. Yang, J. W. Huang, K. Y. Shih, et al., "Factors Associated with Increased Plasma Homocysteine in Patients Using an Amino Acid Peritoneal Dialysis Fluid," Nephrology Dialysis Transplantation, Vol. 20, No. 1, 2005, pp. 161-166. doi:10.1093/ndt/gfh554

[28] S. Haas, C. P. Schmitt, K. Arbeiter, K. E. Bonzel, M. Fischbach, U. John, A. K. Pieper, T. P. Schaub, J. Passlick-Deetjen and O. Mehls, "Schaefer FImproved Acidosis Correction and Recovery of Mesothelial Cell Mass with Neutral-pH Bicarbonate Dialysis Solution among Children Undergoing Automated Peritoneal Dialysis," Journal of the American Society of Hypertension, Vol. 14, No. 10, 2003, pp. 2632-2638. doi:10.1097/01.ASN.0000086475.83211.DF

[29] D. Ducloux, L. Heuze-Lecornu, R. Gibey, C. BressonVautrin, P. Vautrin and J. M. Chalopin, "Dialysis Adequacy and Homocyst(e)ine Concentrations in Peritoneal Dialysis Patients," Nephrology Dialysis Transplantation, Vol. 14, No. 3, 1999, pp. 728-731.

doi:10.1093/ndt/14.3.728

[30] A. Vychytil, M. Fodinger, M. Papagiannopoulos, et al., "Peritoneal Elimination of Homocysteine Moieties in Continuous Ambulatory Peritoneal Dialysis Patients," Kidney International, Vol. 55, No. 5, 1999, pp. 2054 2061. doi:10.1046/j.1523-1755.1999.00437.x 